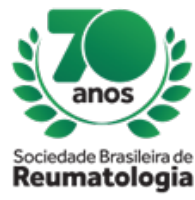

\title{
ARE DIAGNOSTIC CRITERIA FOR SPONDYLARTHRITIS SUITABLE TO PATIENTS WITH ENTHESITIS- RELATED ARTHRITIS? A NINE-YEAR EXPERIENCE OF A PEDIATRIC RHEUMATOLOGY UNIT IN CEARA
}

Eduardo Cesar Rios-Neto (Hospital Geral Waldemar de Alcântara, Fortaleza, CE, Brasil), Mariana Nobre Almeida Dias (Hospital Geral Waldemar de Alcântara, Fortaleza, CE, Brasil), Gabriela Coutinho Gondim Justa (Hospital Geral de Fortaleza, Fortaleza, CE, Brasil), Larissa Oliveira Ribeiro (Centro Universitário Unichristus, Fortaleza, CE, Brasil), Lília Torquilho Almeida (Centro Universitário Unichristus, Fortaleza, CE, Brasil), Júlia Couto Roriz Loiola (Centro Universitário Unichristus, Fortaleza, CE, Brasil), Deyzilene Cardoso Araújo (Centro Universitário Unichristus, Fortaleza, CE, Brasil), Larissa Elias Pinho (Hospital Geral de Fortaleza, Fortaleza, CE, Brasil), Carlos Nobre Rabelo-Júnior (Hospital Geral de Fortaleza, Fortaleza, CE, Brasil), Marco Felipe Castro Silva (Hospital Geral de Fortaleza, Fortaleza, CE, Brasil), Míria Paula Vieira Cavalcante (Hospital Geral de Fortaleza, Fortaleza, CE, Brasil)

\section{BACKGROUND}

Enthesitis-related arthritis (ERA) comprises about $10 \%$ of all subtypes of juvenile idiopathic arthritis (JIA). It is considered an undifferentiated spondyloarthropathy compared to adult forms, with high prevalence of HLA-B27 and risk of sacroiliitis. However, criteria for spondyloarthropathies are neither validated nor routinely applied to ERA patients.

\section{MATERIALS AND METHODS}

A retrospective, observational, quantitative study was carried out by reviewing medical charts of ERA patients (ILAR criteria) with follow up between 2010 and 2019. For comparative purposes, peripheral spondyloarthritis (pSpA) and axial spondyloarthritis (aSpA) criteria according to ASAS were applied. Demographic data, clinical manifestations, laboratory tests and treatment were evaluated. Data were collected in May 2019. Results are presented as number (frequency) or mean and compared using Fisher's exact test.

\section{RESULTS}

A total of 88 patients fulfilled ERA criteria, of which $77(87.5 \%)$ were male. The mean age at symptoms onset, age at diagnosis and interval between symptoms onset to diagnosis was 10.4 (3-17), 12.4 (4.217.6), 2.8 (0-11.5) years, respectively. Arthritis, especially affecting lower limbs, was identified in all patients, enthesitis in 68 (77\%) and inflammatory low back pain in 47 (53\%). HLA-B27 was detected in 61 (69\%) patients. Magnetic resonance imaging (MRI) of sacroiliacs was performed in 64 patients, 47 (73\%) with suggestive alterations of sacroiliitis. After an average of 3.9 years of follow-up, 86 (98\%) patients met criteria for pSpA and 70 patients (80\%) for aSpA. Patients with HLA-B27 fulfilled aSpA criteria more frequently than patients without HLA-B27 ( $90 \%$ vs. $55 \%$; $p=0.0005)$. Patients who met criteria for aSpA had a higher frequency of sacroiliitis in the image compared to those who did not ( $63 \%$ vs. $0 \% ; p=0.0001)$. The most commonly used medications as first-line therapy were nonsteroidal anti-inflammatory drugs (74\%), methotrexate (49\%) and sulfasalazine (30\%). At last visit, 33/77 (42\%) had achieved remission status on medication and 14/72 (19\%) remission without medication. Seventeen patients (19\%) lost follow-up, $44(50 \%)$ remained on follow-up and 27 (31\%) were transferred to adult rheumatology clinic.

\section{CONCLUSION}

It was demonstrated a high frequency of patients with ERA who also met ASAS criteria for pSpA. In fact, literature shows that only after approximately five years do the children evolve with sacroiliitis, which is similar to our mean follow-up time. Our results corroborate that ASAS criteria both for pSpA and aSpA might be extended to the pediatric age group. It would provide early diagnosis, including axial involvement, as well as prompt treatment, thus reducing the burden of long-term complications. 